\title{
From call to action: a roadmap to sustainable conferences
}

\author{
Laure Cugnière $^{1^{*}}$, Diogo Veríssimo ${ }^{1,2}$, Angeles Branas ${ }^{3}$ and Guy Bigwood ${ }^{4,5}$ \\ 1. Department of Zoology, University of Oxford, Oxford, United Kingdom \\ 2 Institute for Conservation Research, San Diego Zoo Global, San Diego, United States of America \\ 3. Freelance Event Manager, Buenos Aires, Argentina \\ 4. Global Destination Sustainability Index, Brussels, Belgium \\ 5. GuBi Consulting \\ * Corresponding Author: 01865 271212, laure.cugniere@zoo.ox.ac.uk
}

\begin{abstract}
There have been numerous calls across the scientific community, in recent years, for research conferences to embrace sustainability. With growing public consciousness and the challenging context posed by climate change both economically, socially and for biodiversity, researchers should be leading the path towards sustainable event planning. In this article, we propose key performances indicators that not only prioritize environmental goals, but also integrate socio-economic considerations at the roots of the planning cycle. We further discuss the added risks and remaining barriers, at the host organisation and destination levels, to plan a sustainable event. By changing the way that research conferences are organized, the scientific community can incorporate their values, knowledge and passion to strengthen existing standards and frameworks. We hope that, as event sustainability becomes more salient and institutions more prone to sharing lessons learned, sustainable events become the norm for all research conferences and meetings.
\end{abstract}

Keywords: Congress, Corporate and Social Responsibility, Environmental Footprint, Event planning, Meeting, Impact 
In the last decade, there have been multiple calls in leading scientific journals for research conferences to become sustainable both environmentally and socially (Fraser et al., 2017; Bossdorf et al., 2010; Meeting expectations, 2008). In the challenging context posed by climate change and biodiversity loss, it is long overdue for those planning conferences to confront their environmental and social cost. The scientific community should be leading the way in designing a conference planning cycle that incorporates a clear sustainable impact pathway with strong socio-environmental goals.

In this article, we provide the perspective of the event planners and professional societies who drive many of those events to support their members in advancing research, as their viewpoint is least represented in the ongoing debate. We propose key performance indicators for sustainable conferences that not only prioritize environmental goals, but also integrate socio-economic considerations at the roots of the planning cycle. Finally, we address the remaining challenges we identified when planning a sustainable conference and reflect how these may be overcome.

\section{Professional societies and conferences}

Conferences are a vital part of the research process, providing researchers with a platform to present and receive feedback on their latest work, to identify new collaborators and develop new ideas. Unfortunately, those events also represent a major part of a researcher's carbon footprint (Bossdorf et al., 2010, Rosen, 2017, Achten et al., 2013). Despite this known impact on climate change and the broader natural environment, and the overlooked impact on local socio-economic development, most conferences have little to no sustainability strategy (Holden et al., 2017). This conundrum is particularly present for events organized by institutions linked to environmental conservation or natural resource management whose attendees are most commonly focused on protecting the very environment the event may well damage. 
At the same time, with a growing public consciousness and related increased importance in terms of corporate image, the private sector has seen, in the last decade, a trend in mainstreaming sustainable event management. This is exemplified by the creation of international standards and frameworks for sustainable event management (e.g., ISO 20121 Event Sustainability Management Systems Standard, APEX Environmentally Sustainable Meeting Standards, and GRI G4 Guidelines and the Event Organizers Sector Disclosures). The scientific community should maximize the use of these tools and use the broad expertise of the private sector to further improve its sustainability track record.

\section{Sustainable conference framework}

In this context, we propose a sustainable research conference strategy (see table 1 ) that draws its core principles and structure from key international sustainable standards, while catering to the research communities' goals and values. This strategy should be implemented throughout the event planning cycle from design to implementation (Ahmad et al., 2013). It includes key measurable performance indicators to ensure a transparent assessment of the achievement and inform future event planning by sharing lessons learned.

Table 1. Examples of goals for a sustainable event

\begin{tabular}{|c|c|c|c|}
\hline & Issue & Objective & Key Performance Indicators \\
\hline \multirow[t]{2}{*}{ Reduce } & Waste & $\begin{array}{l}\text { Switch to sustainable } \\
\text { materials, minimize waste } \\
\text { and increase waste } \\
\text { diversion }\end{array}$ & $\begin{array}{l}50 \% \text { waste diversion rate } \\
\% \text { signage/ lanyards/ bags/ badges made } \\
\text { from sustainable materials }\end{array}$ \\
\hline & $\begin{array}{l}\text { Energy and } \\
\text { emissions }\end{array}$ & $\begin{array}{l}\text { Reduce energy usage, } \\
\text { greenhouse gas emissions } \\
\text { and offset }\end{array}$ & $\begin{array}{l}\text { Measure and analyse carbon emissions } \\
\text { Offset } 100 \%\end{array}$ \\
\hline \multirow[t]{2}{*}{ Rethink } & $\begin{array}{l}\text { Food and } \\
\text { beverage }\end{array}$ & $\begin{array}{l}\text { Offer healthier, tastier and } \\
\text { responsibly sourced food } \\
\text { and beverages }\end{array}$ & $\begin{array}{l}50 \% \text { local sourcing } \\
10 \% \text { organic } \\
50 \% \text { vegetarian }\end{array}$ \\
\hline & Supply chain & $\begin{array}{l}\text { Increase engagement, } \\
\text { innovation and } \\
\text { performance }\end{array}$ & $\begin{array}{l}90 \% \text { of key suppliers signing key } \\
\text { sustainability agreement } \\
90 \% \text { of key suppliers supplying data }\end{array}$ \\
\hline
\end{tabular}


Use indigenous product for some event materials

\begin{tabular}{|c|c|c|c|}
\hline \multirow[t]{6}{*}{ Regenerate } & Engagement & $\begin{array}{l}\text { Gauge feedback on success } \\
\text { of initiative }\end{array}$ & $\begin{array}{l}75 \% \text { of event attendees consider the } \\
\text { sustainability program as an excellent } \\
\text { initiative }\end{array}$ \\
\hline & Protect & $\begin{array}{l}\text { Invest in Colombian } \\
\text { conservation initiatives }\end{array}$ & $\begin{array}{l}\text { Investment to further national } \\
\text { conservation }\end{array}$ \\
\hline & Catalyse & $\begin{array}{l}\text { Invest in global } \\
\text { conservation initiatives }\end{array}$ & $\begin{array}{l}\text { Return on investment reinvested into the } \\
\text { society's mission }\end{array}$ \\
\hline & & $\begin{array}{l}\text { Catalyse further actions } \\
\text { locally }\end{array}$ & Local media, school engagement metrics \\
\hline & Legacy & $\begin{array}{l}\text { Impact the local } \\
\text { destination leaving a } \\
\text { positive legacy }\end{array}$ & $\begin{array}{l}\text { BioBlitz (i.e., biological survey event } \\
\text { aiming at recording as many species as } \\
\text { possible within a designated area by } \\
\text { groups of scientists and volunteers): } \\
\text { community hours participation }\end{array}$ \\
\hline & Educate & $\begin{array}{l}\text { Educate tomorrow's } \\
\text { conservation scientists }\end{array}$ & $\begin{array}{l}\text { Contribution to local economy } \\
\text { \# of programs and travel grants dedicated } \\
\text { to early career professionals }\end{array}$ \\
\hline Respect & Diversity & $\begin{array}{l}\text { Invest in promoting a } \\
\text { diverse, inclusive and } \\
\text { equitable conference }\end{array}$ & $\begin{array}{l}\text { \# of programs dedicated to } \\
\text { underrepresented groups }\end{array}$ \\
\hline Report & Measure & $\begin{array}{l}\text { Measure, assess and } \\
\text { transparently } \\
\text { communicate the } \\
\text { environmental, social and } \\
\text { economic impacts }\end{array}$ & Publicly release Sustainable Event Report \\
\hline
\end{tabular}

We suggest a framework based on eight critical steps:

1. The chosen destination should be central with major international connection to limit the event's carbon footprint related to participants travel. Onsite, walkability and reliable public transport system should be assessed to limit participants carbon footprint further.

2. The contracted venue should ideally already have a system in place to control its carbon emissions, waste and other key environmental impacts, or should be willing to make the appropriate improvements prior to the event.

3. The caterer should prioritize food and beverage that are local, certified, seasonal and plantbased to reduce the event's footprint linked to land use and agro-industrial emissions. 
4. The program of the event will be thought of in a way that limit the need for local transportation once onsite (e.g., city walkability, side-events and field trip locations, one venue fit all).

5. The production, exhibition and communications should be planned using circular design principles so as to limit the need for producing and throwing away materials (paper, plastic, wood etc). Focus should be on rethinking and redesigning stage-sets, brand experiences, exhibition stands and communication material that is made from more sustainable substrates, is recyclable and is recycled/reused. To achieve this, the event team should work closely with suppliers aligned with the sustainability strategy and amenable to collecting key carbon data to assist with the monitoring and evaluation of the event's carbon footprint.

6. The event organizer should engage and inform the event team, donors, exhibitors, participants and the broader community to get buy-in.

7. Equality, inclusion and diversity and the socio-economic legacy of the event should also play a central role in the program design and take the local context into considerations.

8. The event impact must be measured and reported. Event organisers and suppliers need to collaborate to collect, measure and benchmark key actions and performance indicators -- i.e. for water, waste, energy, carbon emissions, food, community and societal impact, and economic contribution.

The UN Sustainable Development Goals provide a very good framework for strategy development, action and reporting of event impacts.

\section{The $2^{\text {th }}$ International Congress for Conservation Biology as a case-study}

The Society for Conservation Biology (SCB) is a global community of nearly 5,000 members, from over 140 countries, dedicated to advancing the science and practice of conserving Earth's biological diversity. To further its mission, SCB hosts biannually the International Congress for Conservation Biology (ICCB) 
which is recognized as one of the most important networking meetings for addressing conservation challenges and presenting new developments in conservation research and practice. The sustainable conference framework described hereinabove was successfully implemented at the $28^{\text {th }}$ ICCB, held in Cartagena de Indias, Colombia, in 2017 (MCl Sustainability Services, 2017).

After evaluation, the carbon footprint of the event amounted to $1371.46 \mathrm{tCo} e \mathrm{e}(\mathrm{MCl}$ Sustainability Services, 2017) which compared to the annual Co2 emissions of 779 Colombians (World Bank). The totality of the suppliers contracted for the event also signed the event's sustainability agreement and provided data for the evaluation of the event's carbon emissions. Key achievements included $87 \%$ reduction of waste, with only $933 \mathrm{~kg}$ of waste produced in place of an estimate 7.4 tons for an average event of this type ( $5 \mathrm{~kg} /$ person). Moreover, $56 \%$ of this waste was diverted from landfill despite the local limitations in recycling infrastructures. As a point of comparison, the UK average equals only $15 \%$ for this type of event.

To reach this outcome, the venue was assisted in setting up a strict new waste management system based on international APEX standards. In an effort to reduce the footprint of the event beyond waste, all beef products were eliminated and $79 \%$ of the event's food was made vegetarian or vegan. The venue's catering team was also trained in designing low footprint catering options. Some of their key achievements included eliminating over $98 \%$ of disposable service ware, reducing food waste by requiring advanced purchase and confirmation, buying Marine Stewardship Council certified salmon and other seafood from local artisan fisherman, offering a broader set of options for vegetarian and vegan options, and sourcing at least $50 \%$ of the food served locally (defined as $<160 \mathrm{~km}$ ). Together with the new waste management system, these ameliorations were fully integrated in the venue's sustainability strategy for a lasting change in their event management strategy. The event team also worked closely with its suppliers - including the venue, to ensure that the best sustainable services and products were 
provided. For the suppliers who did not have a comprehensive sustainability strategy, the planning of ICCB 2017 included an awareness programme to assist them in integrating new long-term policies.

Thanks to the voluntary contribution of the event's participants, about $95 \%$ of the Congress's carbon emissions were offset with the SCB contributing with the funds needed to reach $100 \%$. The USD \$12k fund was dispersed between two internationally certified environmental projects located in the host country Colombia. These used the Gold Standard and the Verified Carbon Standard and are administered by the Fundación Natura Colombia (www.natura.org.co). The Vichada group project for commercial forest plantations initiatives project promotes investments in new sustainable commercial forest plantations, based on changing the land use from extensive cattle ranching to sustainable forest productive systems. The other project was a Cookstove PoA focused initiative designed to provide energy efficient cooking stoves, necessary to meet the needs of an average family in the region, while reducing the need for fuelwood. This is very important as fuelwood consumption (e.g., Andean oak) in the region is a stressing factor for local forests and their communities. Both projects were meticulously selected due to their alignment with the Society's mission by contributing to biodiversity conservation, climate change, social development.

The social legacy of the event locally and for the international conservation community was also considered when planning the sustainability strategy of this event. All registered participants (including exhibitors) were asked to read and understand SCB's Event Code of Conduct which promoted a safe and inclusive environment and presented a clear process for participants to report any unacceptable behaviours. Furthermore, the event team considered inclusivity and safety when selecting the event's destination and Cartagena appear to present a low risk for participants vulnerable to discrimination (e.g., based on ethnicity or sexual orientation). The event was also made parent-friendly, with free access for all children under the age of 16 , the option of onsite childcare at registration and a breastfeeding area and baby changing facilities made available. The changing facilities were easily 
accessible in the gender-neutral bathrooms. This scheme intended to reduce the barriers faced by young parents', particularly women, to participation at professional events. The organisers also aimed to promote diversity in conservation through the careful selection of the keynote speakers (e.g., gender, ethnicity) to highlight a diversity of role models.

To further reduce these barriers, the planning team raised funds to fully sponsor the participation of ten afro-descendant and indigenous leaders from Colombia and bring their voices to the event. Twenty travel grants were also awarded to national and international conservationists from underrepresented groups to attend the meeting. Finally, to make the event as widely accessible as possible and offer the opportunity to conservationists to make the conscious choice not to travel and increase their carbon emissions, key sessions of the event were freely available via livestream and made more accessible through live translation (i.e., English and Spanish). The recording of those sessions was then uploaded post-event and remains freely available online on the Society's Vimeo channel

(https://vimeo.com/society4conbio).

These are overdue changes that should have been in place at previous events, and they are also a necessary step in the right direction for the society to unburden its participants from driving equality, diversity and inclusivity considerations. If these efforts are maintained over time, the society can position itself as a driver of lasting changes in the global conservation community. Moving towards more sustainable event planning should not be about perfection from event one but about a continuous improvement, learning from preceding meetings, local needs and incorporating the industry's latest innovations (Ahmad et al., 2013) for a lasting change. However, and despite these encouraging results which any society can integrate into their sustainability strategy moving forward, key barriers remain. 


\section{Remaining challenges}

Planning an international event that caters to a broad audience with varied cultural background and diverse social values and environmental priorities can represent a challenge. In this context, including a clear sustainability strategy to the event planning cycle is also an added risk for the event planners as some of the key barriers are often at the institutional and destination-level.

Institutional-level challenges

Sustainability is not often a priority when considering the planning of a conference and is not regularly build-in the core event strategy of the organization leading its planning. Without a champion to push this added agenda, it oftentimes remains an after-thought if at all considered. This is reinforced by the fact that many organizing institutions, such as professional societies, rely on rotating volunteer committees for the planning of those events which limits the opportunity to learn from experience and standardize the planning process over time (Holden et al., 2017).

Additionally, while those leading the organization may have the passion to push a sustainability agenda forward for the event, they are planning they often lack the resources or set of skills required to design, implement and evaluate a full sustainability strategy. There needs to be a real commitment at the leadership level from the institutions leading the organization of the event as well as commitment to institutional-level change. This is the only way to avoid fickle commitments to sustainability that depend on the interest of one or a few individuals, who may not be involved in future events, as well as reduce the risk of perceived greenwashing (Griese et al., 2017).

\section{Destination-level challenges}

Depending on the destination selected for the event, some indicators may be more difficult to achieve due to, for example, cultural differences or lack of infrastructure. A destination may be well equipped to 
plan a sustainable event but may not be suited for diversity and inclusivity concerns (e.g., visa barriers, LGBTQ+ rights, cost of participation). What is more, the interpretation of what is socially acceptable, or what promotes or impairs equality, inclusion and diversity goals may depend on the unique background of each participant which risks creating further strains when planning a socially sustainable conference for a global audience.

For environmental and economic considerations, local suppliers should be prioritized whenever possible, however local markets may not be up to international sustainability standards. As such, those suppliers may not be equipped to cater to the requirements of an event's strategy based on international best practices (e.g., availability of sustainable materials or adapted local infrastructure). Local limitations will also lengthen the planning timeline and may require specific contract negotiation and added time investment at the implementation level, which in turn may increase the financial risk and hinder the delivery of a quality event.

\section{Your turn}

Despite those challenges, there is an increasing number of sustainable conferences being organized (Ahmad et al., 2013), and international standards, guidelines and lessons learned are readily available (Holden et al., 2017). It is time for the research community to "walk the talk" and renew their commitment to mitigating environmental and social impacts. Based on our experience planning a conference which incorporated a full sustainability strategy, we hope this framework and the lessons learned below can help other professional societies to design and implement stronger sustainability strategies for future research conferences:

- Start early - Remember to start early and include social, economic and environmental sustainability into your core event strategy from the kick-off meeting and throughout the entire planning cycle. 
- SDGS - The 17 UN Sustainable Development Goals provide an excellent framework and a shared language for sustainability. They offer an easy way to focus action on selected SDG goals that align with the organisation and scientific mission. The also provide a universally accepted structure for reporting and communicating on event impacts.

- Location - Select a destination with sustainability in mind. When considering sustainability performance, specific destinations (i.e., central with hub airport) and venues offer better performance opportunities which should impact the selection process. There are two options, to either pick a destination based on sustainability commitment and services already in place or select a destination with no existing sustainability services but willing to develop new practices. The second option as the advantage of increasing the legacy of the event, however, the implementation timeline will likely be lengthened. The Global Destination Sustainability Index (www.gds-index.com) is a great resource to find sustainable host locations.

- Resources -- Commit appropriate resources. This type of conferences is often planned on a budget with limited staff and relying on volunteers. Yet, ambitious sustainable goals should be supported by the organization committing appropriate resources to its design, implementation and evaluation including a dedicated staff or volunteers and a clear fundraising strategy as well as. Although it requires an initial investment, hiring expert consultants can (and should) deliver significant costs savings and environmental and social performance improvements.

- Contracting strategy - Engage your suppliers from the first moment. The sustainability requirements and policy must be included into the suppliers sourcing and contracting process to ensure a binding commitment to action and reporting on key indicators; therefore, ensuring the full evaluation of the event's impact. 
- Engage and educate - Involve all your participants. All staff, volunteers, sponsors and participants need to be aware of the policy, its goals and their own role in making a more sustainable event.

- Legacy - Leave a positive socio-economic footprint behind. The organisation should take action to support local researchers, contribute to the local community, inspire local suppliers to adopt internationally recognised best practices, offset the events carbon emissions regionally, and promote social inclusivity and diversity.

By changing the way that research conferences are organized, professional societies and other institutions involved in the organisation of these events can live by the social and environmental standards they advocate for. It is also a chance to lead the way by incorporating the values, knowledge and passion of the research community to strengthen existing sustainability standards and frameworks. We hope that as event sustainability becomes more salient and institutions more prone to sharing lessons learned the standards above become the norm for all not-for-profit and research events.

\section{Acknowledgements}

We would like to recognise the joint effort made by the amazing staff of the Society for Conservation Biology and the ICCB 2017 organising committees to plan the $28^{\text {th }}$ International Congress for Conservation Biology using the benchmarks described in this article. We are particularly grateful to Warren Sander and Mike Mascia who have supported this initiative from the start. 


\section{References}

Achten W.M.J., Almeida J., Muys B. 2013. Carbon footprint of science: More than flying, Ecological Indicators, Vol 34: 352-355.

Ahmad N. L., Rashid W. E. W., Razak N. A., Yusof A. N. M., Shah N. S. M. 2013. International Journal of Trade, Economics and Finance. Vol 4 (5): 331-335.

Bossdorf O., Parepa M., Fischer M. 2010. Climate-neutral ecology conferences: just do it! Trends Ecol. Evol. Vol 25: 61 .

Fraser H., Soanes K., Jones A. S., Jones S. C., Malishev M. 2017. The value of virtual conferencing for ecology and conservation. Conservation Biology, Vol 31 (3): 540-546.

Griese K.M., Werner K., Hogg J. 2017. Avoiding Greenwashing in Event Marketing: An Exploration of Concepts, Literature and Methods. Journal of Management and Sustainability; Vol 7 (4).

Holden M. H., Butt N., Chauvenet A., Plein M., Stringer M., Chadès I. 2017. Academic conferences urgently need environmental policies. Nature Ecology \& Evolution. Vol 1: 1211-1212.

Meeting expectations. Editorial. Nature. Vol 455: 836. 2008.

Rosen J. 2017. A greener culture. Nature; Vol 546: 565-567.

MCI Sustainability Services. 2017. $28^{\text {th }}$ International Congress for Conservation Biology - Event Sustainability Report 2017. Society for Conservation Biology. Available at https://conbio.org/images/content_conferences/10.25_ICCB_sustainability_report_final_lowres.pdf (25 May 2019).

World Bank. CO2 emissions (metric tons per capita). Available at https://data.worldbank.org/indicator/en.atm.co2e.pc 